
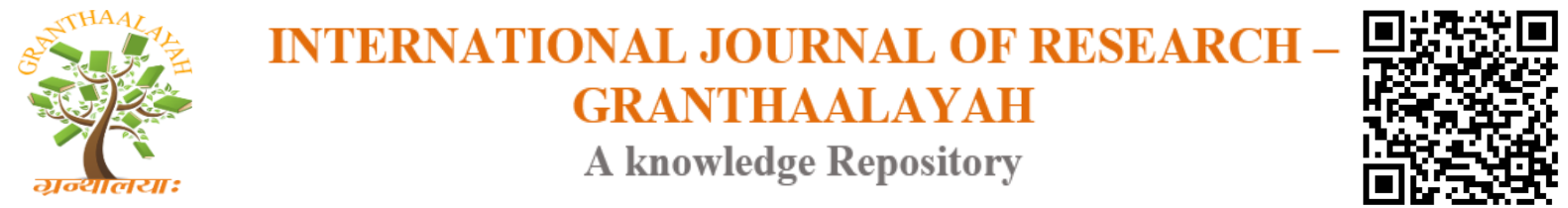

Science

\title{
A NOVEL HYBRIDIZED ALGORITHM FOR REDUCTION OF REAL POWER LOSS
}

\author{
Dr.K.Lenin *1 \\ ${ }^{* 1}$ Professor, Department of EEE, Prasad V.Potluri Siddhartha Institute of Technology, Kanuru, \\ Vijayawada, Andhra Pradesh -520007, India
}

\begin{abstract}
This paper proposes Hybridization of Gravitational Search algorithm with Simulated Annealing algorithm (HGS) for solving optimal reactive power problem. Individual position modernize strategy in Gravitational Search Algorithm (GSA) may cause damage to the individual position and also the local search capability of GSA is very weak. The new HGS algorithm introduced the idea of Simulated Annealing (SA) into Gravitational Search Algorithm (GSA), which took the Metropolis-principle-based individual position modernize strategy to perk up the particle moves, \& after the operation of gravitation, Simulated Annealing operation has been applied to the optimal individual. In order to evaluate the efficiency of the proposed Hybridization of Gravitational Search algorithm with Simulated Annealing algorithm (HGS), it has been tested on standard IEEE 118 \& practical 191 bus test systems and compared to the standard reported algorithms. Simulation results show that HGS is superior to other algorithms in reducing the real power loss and voltage profiles also within the limits.
\end{abstract}

Keywords: Simulated Annealing; Gravitational Search Algorithm; Optimal Reactive Power; Transmission Loss.

Cite This Article: Dr.K.Lenin. (2017). "A NOVEL HYBRIDIZED ALGORITHM FOR REDUCTION OF REAL POWER LOSS.” International Journal of Research - Granthaalayah, 5(11), 316-324. https://doi.org/10.29121/granthaalayah.v5.i11.2017.2358.

\section{Introduction}

Power system reliability is connected through security, and it mentions to dependability of service, evenness in frequency and particular voltage limitations. Optimal reactive power dispatch is one among the key subject for the operation and control of power systems, and it should be carried out properly such that system dependability should not get affected. The gradient method [1, 2], Newton method [3] and linear programming [4-7] experience from the complexity of managing the inequality constraints. In recent times extensive Optimization techniques such as genetic algorithms have been projected to solve the reactive power flow problem [8-10].Gravitational Search Algorithm (GSA) [11] is proposed by Professor Esmat Rashedi of Blackman University of Iranian in 2009. The GSA algorithm is based on Newton's 
law of universal gravitation, and guides the particles in exploration through simulated particleparticle communication. The algorithm without local search mechanism is weak in local exploration ability which thus pulls down the convergence speed and accurateness. According to the above stated disadvantages of GSA, this paper project's Hybridization of Gravitational Search algorithm with Simulated Annealing algorithm (HGS) for solving reactive power problem. Individual position modernize strategy in Gravitational Search Algorithm (GSA) may cause damage to the individual position and also the local search capability of GSA is very weak. The new HGS algorithm introduced the idea of Simulated Annealing (SA) into Gravitational Search Algorithm (GSA), which took the Metropolis-principle-based individual position modernize strategy to perk up the particle moves, $\&$ after the operation of gravitation, Simulated Annealing operation has been applied to the optimal individual [12-15]. In order to evaluate the efficiency of the proposed Hybridization of Gravitational Search algorithm with Simulated Annealing algorithm (HGS), it has been tested on standard IEEE 118 \& practical 191 bus test systems and compared to the standard reported algorithms. Simulation results show that HGS is superior to other algorithms in reducing the real power loss and voltage profiles also within the limits.

\section{Problem Formulation}

The optimal power flow problem is treated as a general minimization problem with constraints, and can be mathematically written in the following form:

Minimize $f(x, u)$

subject to $g(x, u)=0$

and

$\mathrm{h}(\mathrm{x}, \mathrm{u}) \leq 0$

where $f(x, u)$ is the objective function. $g(x . u)$ and $h(x, u)$ are respectively the set of equality and inequality constraints. $\mathrm{x}$ is the vector of state variables, and $\mathrm{u}$ is the vector of control variables.

The state variables are the load buses (PQ buses) voltages, angles, the generator reactive powers and the slack active generator power:

$\mathrm{x}=\left(\mathrm{P}_{\mathrm{g} 1}, \theta_{2}, \ldots, \theta_{\mathrm{N}}, \mathrm{V}_{\mathrm{L} 1}, ., \mathrm{V}_{\mathrm{LNL}}, \mathrm{Q}_{\mathrm{g} 1}, \ldots, \mathrm{Q}_{\mathrm{gng}}\right)^{\mathrm{T}}$

The control variables are the generator bus voltages, the shunt capacitors/reactors and the transformers tap-settings:

$\mathrm{u}=\left(\mathrm{V}_{\mathrm{g}}, \mathrm{T}, \mathrm{Q}_{\mathrm{c}}\right)^{\mathrm{T}}$

or

$\mathrm{u}=\left(\mathrm{V}_{\mathrm{g} 1}, \ldots, \mathrm{V}_{\mathrm{gng}}, \mathrm{T}_{1}, \ldots, \mathrm{T}_{\mathrm{Nt}}, \mathrm{Q}_{\mathrm{c} 1}, \ldots, \mathrm{Q}_{\mathrm{cNc}}\right)^{\mathrm{T}}$

Where ng, nt and nc are the number of generators, number of tap transformers and the number of shunt compensators respectively. 


\section{Objective Function}

\subsection{Active Power Loss}

The objective of the reactive power dispatch is to minimize the active power loss in the transmission network, which can be described as follows:

$F=P L=\sum_{k \in N b r} g_{k}\left(V_{i}^{2}+V_{j}^{2}-2 V_{i} V_{j} \cos \theta_{i j}\right)$

or

$F=P L=\sum_{i \in N g} P_{g i}-P_{d}=P_{g s l a c k}+\sum_{i \neq s l a c k}^{N g} P_{g i}-P_{d}$

where $g_{k}$ : is the conductance of branch between nodes $i$ and $j$, Nbr: is the total number of transmission lines in power systems. $\mathrm{P}_{\mathrm{d}}$ : is the total active power demand, $\mathrm{P}_{\text {gi }}$ : is the generator active power of unit $\mathrm{i}$, and $\mathrm{P}_{\text {gsalck: }}$ is the generator active power of slack bus.

\subsection{Voltage Profile Improvement}

For minimizing the voltage deviation in PQ buses, the objective function becomes:

$F=P L+\omega_{v} \times V D$

where $\omega_{\mathrm{v}}$ : is a weighting factor of voltage deviation.

VD is the voltage deviation given by:

$V D=\sum_{i=1}^{N p q}\left|V_{i}-1\right|$

\subsection{Equality Constraint}

The equality constraint $\mathrm{g}(\mathrm{x}, \mathrm{u})$ of the ORPD problem is represented by the power balance equation, where the total power generation must cover the total power demand and the power losses:

$P_{G}=P_{D}+P_{L}$

This equation is solved by running Newton Raphson load flow method, by calculating the active power of slack bus to determine active power loss.

\subsection{Inequality Constraints}

The inequality constraints $\mathrm{h}(\mathrm{x}, \mathrm{u})$ reflect the limits on components in the power system as well as the limits created to ensure system security. Upper and lower bounds on the active power of slack bus, and reactive power of generators: 
$P_{\text {gslack }}^{\min } \leq P_{\text {gslack }} \leq P_{\text {gslack }}^{\max }$

$Q_{g i}^{\min } \leq Q_{g i} \leq Q_{g i}^{\max }, i \in N_{g}$

Upper and lower bounds on the bus voltage magnitudes:

$V_{i}^{\min } \leq V_{i} \leq V_{i}^{\max }, i \in N$

Upper and lower bounds on the transformers tap ratios:

$T_{i}^{\min } \leq T_{i} \leq T_{i}^{\max }, i \in N_{T}$

Upper and lower bounds on the compensators reactive powers:

$Q_{c}^{\min } \leq Q_{c} \leq Q_{C}^{\max }, i \in N_{C}$

Where $\mathrm{N}$ is the total number of buses, $\mathrm{N}_{\mathrm{T}}$ is the total number of Transformers; $\mathrm{N}_{\mathrm{c}}$ is the total number of shunt reactive compensators.

\section{Simulated Annealing Algorithm}

Simulated Annealing (SA) Algorithm is derived from the Solid Annealing Ideological Theory. The solid is heated to an amply high temperature, then left to cool down gradually. Simulated Annealing Algorithm started from a higher initial temperature, then as the temperature parameters drop, combined with arbitrary salvation in the solution space to arbitrarily search the global optimal solution of the objective function, that is, the optimal solution can jump out at local and eventually become a global optimum.

Metropolis principle:

Let the preliminary state of the particle $i$, random perturbation to get a new state of the particle $j$. $E(i), E(j)$ respectively the energy in the state of particles $i, j$.

(1) if $\mathrm{E}(\mathrm{j})<\mathrm{E}(\mathrm{i})$, The state transition is putative ;

(2) if $E(j) \geq E(i)$, The state transition probability is:

$P_{i j}=\exp \left(-\frac{E(j)-E(i)}{K T}\right)$

Where $K$ is the physics terms of Boltzmann constant, $T$ is the temperature of the material.

\section{Gravitational Search Algorithm}

Gravitational Search Algorithm (GSA) is based on the Newton's law of gravitation. Any two particles in the universe attract each other with a force in the direction of the middle line. The formula could be expressed as:

$F=G \frac{M_{1} M_{2}}{R^{2}}$ 
Where $F$ represents the gravity, $G$ represents the gravitational constant, $M_{l}$ and $M_{2}$ respectivelyrepresent the inertial mass of the two particles, and $R$ is the Euclid Distance between two particles.

The attractiveness of particle $j$ to particle $\mathrm{i}$ at dimension $d$ is

$F_{i j}^{d}(t)=G(t) \frac{M_{P i}(t)}{R_{i j}(t)+\varepsilon}\left(x_{j}^{d}(t)-x_{i}^{d}(t)\right)$

Because the experimental result of $R$ is better than that of $R^{2}$, use $R$ instead of using $R^{2} ; R_{i j}$ represents the mass of exert force particle $j, M_{p i}$ represents the mass of stressed particle $i$; $\varepsilon$ is a smallconstant, $G(\mathrm{t})$ is the gravitational constant at time $t$ :

$G(t)=G_{o} e^{-\alpha \frac{t}{T}}$

Where $G_{0}$ is the initial gravitational constant, $\alpha$ is a constant, $T$ is the total number of iterations ofthe algorithm.Pool efforts of particle $i$ at dimension $d$ :

$F_{i}^{d}(t)=\sum_{j=1 . j \neq i}^{N}$ rand $\times F_{i j}^{d}(t)$

Here rand is an arbitrary quantity added to increase the arbitrariness of the search algorithm, which ranges $[0,1]$.

According to the Newton's second law: at time $t$, the acceleration of particle ion d:

$a_{i}^{d}(t)=\frac{F_{i}^{d}(t)}{M_{i}(t)}$

Here $M_{i}(t)$ is the inertial mass of particle $i$.

In GSA, the following formulas are used to renovate the inertial mass of the particle:

$M_{a i}=M_{p i}=M_{i i}=M_{i},(i=1,2,3, \cdot, N)$

$m_{i}(t)=\frac{\text { fit }_{i}(t)-\operatorname{worst}(t)}{\operatorname{best}(t)-\operatorname{worst}(t)}$

$m_{i}(t)=\frac{m_{i}(t)}{\sum_{j=1}^{N} m_{j}(t)}$

Here fit $(t)$ is the fitness value of particle. For the minimum problem, worst $(t)$ and best $(t)$ are defined as follow:

$$
\begin{aligned}
& \operatorname{best}(t)=\underbrace{\min }_{j \in\{1,,, N\}} f_{j}(t) \\
& \operatorname{worst}(t)=\underbrace{\max }_{j \in\{1,, N\}} f i t_{j}(t)
\end{aligned}
$$


In GSA, every attempt of iteration will update particles motion state in harmony with Newton's laws of motion. The formula is:

$V_{i}^{d}(t+1)=\operatorname{rand} \times V_{i}^{d}(t)+a_{i}^{d}(t)$

$x_{i}^{d}(t+1)=x_{i}^{d}(t)+v_{i}^{d}(t)$

Where rand is a random number from $[0,1], V_{i}^{d}(\mathrm{t})$ and $x_{i}^{d}(\mathrm{t})$ respectively represents the speed and position proportion at dimension $d$ of particle $i$ at time $t$.

Algorithm Improvement Based on Simulated Annealing based on Position update strategy based on Metropolis principle. Equation (29) shows that the updating of particle position is to some degree of arbitrary, so the individual may transfer from higher-fitness-value position to lowerfitness-value position. This manifestation is called individual degradation, i.e. this may cause $f i t_{i+1}(t)>f i t_{i}(t)$ (for the minimum problem), which is detectably harmful for solving the problem. To make up for the defect of gravitational algorithm, this paper, based on the Metropolis principle, projected new strategies of particle position update: first use equation (29) to compute the next position of particle $i \bar{x}_{l}(t+1)$; then use Metropolis principle to define whether to accept $\overline{x_{l}}(t+1)$ as the next position of $i$. Details as follow:

if fit $_{i+1}(t) \leq f i t_{i}(t)$ or rand $\leq \exp \left(-\frac{\text { fit }_{i+1}(t)-f i t_{i}(t)}{K T}\right), x_{i}(t+1)=\bar{x}_{l}(t+1)$; else $x_{i}(t+$

1) $=x_{i}(t)$

Where $f i t_{i+1}(t)$ is the fitness value of next possible position, $\bar{x}_{l}(t+1)$ of $i$, rand is a random parameter from $[0,1]$. $f i t_{i+1}(t)$ is the fitness value when $\bar{x}_{l}(t+1)$ is assumed to be the next possible position of $i$, rand is a random parameter from $[0,1]$.

\section{Hybridization of Gravitational Search Algorithm with Simulated Annealing Algorithm (HGS) for Solving Reactive Power Problem}

Gravitational Search Algorithm has resilient global exploration ability; however, from the concrete steps of this algorithm we find it paucity of local exploration mechanism. Simulated Annealing Algorithm though not tremendous in global searching at early stage, but can rapidly search the local optimal solution. Therefore, this paper combined Gravitational Search Algorithm with Annealing Algorithm to coagulate the algorithm both the global and local search capabilities. The Gravitational Search Algorithm Based on Simulated Annealing observed with the basic frame of GSA adopted the particle position update strategy based on Metropolis principle, and then when the gravitational algorithm is complete, use the optimal annealing to operate the optimal individual to raise the capability of local optimization algorithms.

Step a. Initialization: preliminary index $\mathrm{Q}$, preliminary gravitational constant $\mathrm{G}_{0}$, the preliminary annealing temperature $\mathrm{T}_{0}$, Boltzmann constant $\mathrm{K}$, iterations $\mathrm{N}$.

Step b. Compute the particle fitness value.

Step c. Update gravitational Parameter $G(t)$, best $(\mathrm{t})$, worst $(\mathrm{t})$, and the inertial mass of the particle $M_{i}(t)$. 
Step d. Use equation (21) to compute the sum of the force in each direction.

Step e. Estimate the acceleration and velocity of each particle respectively according to equations (22) \& (38).

Step f. Calculate the next possible position of each particle according to equation (29). Use position update strategies in Metropolis principle to update the particle position.

Step g. Operate the annealing of optimal Individuals.

Step h. Determine the end of the iteration. If not end, then return to step c and repeat.

Step i. Output the result.

\section{Simulation Results}

At first Hybridization of Gravitational Search algorithm with Simulated Annealing algorithm (HGS) has been tested in standard IEEE 118-bus test system [16].The system has 54 generator buses, 64 load buses, 186 branches and 9 of them are with the tap setting transformers. The limits of voltage on generator buses are 0.95 -1.1 per-unit., and on load buses are 0.95 -1.05 per-unit. The limit of transformer rate is $0.9-1.1$, with the changes step of 0.025 . The limitations of reactive power source are listed in Table 1, with the change in step of 0.01 .

Table 1: Limitation of reactive power sources

\begin{tabular}{|l|l|l|l|l|l|l|l|}
\hline BUS & 5 & 34 & 37 & 44 & 45 & 46 & 48 \\
\hline QCMAX & 0 & 14 & 0 & 10 & 10 & 10 & 15 \\
\hline QCMIN & -40 & 0 & -25 & 0 & 0 & 0 & 0 \\
\hline BUS & 74 & 79 & 82 & 83 & 105 & 107 & 110 \\
\hline QCMAX & 12 & 20 & 20 & 10 & 20 & 6 & 6 \\
\hline QCMIN & 0 & 0 & 0 & 0 & 0 & 0 & 0 \\
\hline
\end{tabular}

The statistical comparison results of 50 trial runs have been list in Table 2 and the results clearly show the better performance of proposed HGS algorithm.

Table 2: Comparison results

\begin{tabular}{|l|l|l|l|l|}
\hline Active power loss (p.u) & $\begin{array}{l}\text { BBO } \\
{[17]}\end{array}$ & $\begin{array}{l}\text { ILSBBO/ } \\
\text { strategy1 } \\
{[\mathbf{1 7}]}\end{array}$ & $\begin{array}{l}\text { ILSBBO/ } \\
\text { strategy1 } \\
{[\mathbf{1 7 ]}}\end{array}$ & $\begin{array}{l}\text { Proposed } \\
\text { HGS }\end{array}$ \\
\hline Min & 128.77 & 126.98 & 124.78 & 114.92 \\
\hline Max & 132.64 & 137.34 & 132.39 & 118.34 \\
\hline Average & 130.21 & 130.37 & 129.22 & 116.58 \\
\hline
\end{tabular}

Then Hybridization of Gravitational Search algorithm with Simulated Annealing algorithm (HGS) has been tested in practical 191 test system and the following results have been obtained. In Practical 191 test bus system - Number of Generators $=20$, Number of lines $=200$, Number of buses $=191$ Number of transmission lines $=55$. Table 3 shows the optimal control values of practical 191 test system obtained by HGS method. And table 4 shows the results about the value of the real power loss by obtained by HGS algorithm. 
Table 3: Optimal Control values of Practical 191 utility (Indian) system by HGS method

\begin{tabular}{|c|c|c|c|c|c|c|c|}
\hline \multicolumn{2}{|l|}{ VG1 } & \multicolumn{2}{|l|}{1.10} & & \multicolumn{2}{|l|}{ VG 11} & 0.90 \\
\hline VG 2 & & \multicolumn{2}{|l|}{0.76} & & \multicolumn{2}{|l|}{ VG 12} & 1.00 \\
\hline VG 3 & & \multicolumn{2}{|l|}{1.01} & & \multicolumn{2}{|l|}{ VG 13} & 1.00 \\
\hline VG 4 & & \multicolumn{2}{|l|}{1.01} & & \multicolumn{2}{|l|}{ VG 14} & 0.90 \\
\hline VG 5 & & \multicolumn{2}{|l|}{1.10} & & \multicolumn{2}{|l|}{ VG 15} & 1.00 \\
\hline VG 6 & & \multicolumn{2}{|l|}{1.10} & & \multicolumn{2}{|l|}{ VG 16} & 1.00 \\
\hline VG 7 & & \multicolumn{2}{|l|}{1.10} & & \multicolumn{2}{|l|}{ VG 17} & 0.90 \\
\hline VG 8 & & \multicolumn{2}{|l|}{1.01} & & \multicolumn{2}{|l|}{ VG 18} & 1.00 \\
\hline VG 9 & & \multicolumn{2}{|l|}{1.10} & & \multicolumn{2}{|l|}{ VG 19} & 1.10 \\
\hline VG 10 & & \multicolumn{2}{|c|}{1.01} & & \multicolumn{2}{|l|}{ VG 20} & 1.10 \\
\hline $\mathrm{T} 1$ & \multicolumn{2}{|l|}{1.00} & $\mathrm{~T} 21$ & 0.90 & & $\mathrm{~T} 41$ & 0.90 \\
\hline $\mathrm{T} 2$ & 1.00 & & T22 & 0.90 & & $\mathrm{~T} 42$ & 0.90 \\
\hline T3 & 1.00 & & T23 & 0.90 & & $\mathrm{~T} 43$ & 0.91 \\
\hline $\mathrm{T} 4$ & 1.10 & & T24 & 0.90 & & $\mathrm{~T} 44$ & 0.91 \\
\hline T5 & 1.00 & & T25 & 0.90 & & $\mathrm{~T} 45$ & 0.91 \\
\hline T6 & 1.00 & & T26 & 1.00 & & $\mathrm{~T} 46$ & 0.90 \\
\hline $\mathrm{T} 7$ & 1.00 & & T27 & 0.90 & & $\mathrm{~T} 47$ & 0.91 \\
\hline $\mathrm{T} 8$ & 1.01 & & T28 & 0.90 & & $\mathrm{~T} 48$ & 1.00 \\
\hline T9 & 1.00 & & T29 & 1.01 & & T49 & 0.90 \\
\hline T10 & 1.00 & & T30 & 0.90 & & T50 & 0.90 \\
\hline T11 & 0.90 & & T31 & 0.90 & & T51 & 0.90 \\
\hline T12 & 1.00 & & T32 & 0.90 & & T52 & 0.90 \\
\hline T13 & 1.01 & & T33 & 1.01 & & T53 & 1.00 \\
\hline T14 & 1.01 & & T34 & 0.90 & & T54 & 0.90 \\
\hline $\mathrm{T} 15$ & 1.01 & & T35 & 0.90 & & T55 & 0.90 \\
\hline T19 & 1.02 & & T39 & 0.90 & & & \\
\hline $\mathrm{T} 20$ & 1.01 & & T40 & 0.90 & & & \\
\hline
\end{tabular}

Table 4: Optimum real power loss values obtained for practical 191 utility (Indian) system by HGS method

\begin{tabular}{l|l}
\hline $\begin{array}{l}\text { Real power Loss } \\
(\mathrm{MW})\end{array}$ & HGS \\
\hline Min & 142.992 \\
\hline Max & 146.574 \\
\hline Average & 144.048 \\
\hline
\end{tabular}

\section{Conclusion}

In this paper Hybridization of Gravitational Search algorithm with Simulated Annealing algorithm (HGS) is successfully solved the optimal reactive power problem. The new HGS algorithm introduced the idea of Simulated Annealing (SA) into Gravitational Search Algorithm (GSA), which took the Metropolis-principle-based individual position modernize strategy to perk up the particle moves, \& after the operation of gravitation, Simulated Annealing operation has 
been applied to the optimal individual. In order to evaluate the efficiency of the proposed Hybridization of Gravitational Search algorithm with Simulated Annealing algorithm (HGS), it has been tested on standard IEEE 118 \& practical 191 bus test systems and compared to the standard reported algorithms. Simulation results show that HGS is superior to other algorithms in reducing the real power loss and voltage profiles also within the limits.

\section{References}

[1] O.Alsac, and B. Scott, "Optimal load flow with steady state security”, IEEE Transaction. PAS 1973, pp. 745-751.

[2] Lee K Y ,Paru Y M , Oritz J L -A united approach to optimal real and reactive power dispatch , IEEE Transactions on power Apparatus and systems 1985: PAS-104 : 1147-1153

[3] A.Monticelli , M .V.F Pereira ,and S. Granville , "Security constrained optimal power flow with post contingency corrective rescheduling", IEEE Transactions on Power Systems :PWRS-2, No. 1, pp.175-182.,1987.

[4] Deeb N, Shahidehpur S.M, Linear reactive power optimization in a large power network using the decomposition approach. IEEE Transactions on power system 1990: 5(2) : 428-435

[5] E. Hobson ,'Network consrained reactive power control using linear programming, ' IEEE Transactions on power systems PAS -99 (4) ,pp 868-877, 1980

[6] K.Y Lee, Y.M Park, and J.L Oritz, "Fuel -cost optimization for both real and reactive power dispatches", IEE Proc; 131C,(3), pp.85-93.

[7] M.K. Mangoli, and K.Y. Lee, "Optimal real and reactive power control using linear programming”, Electr.Power Syst.Res, Vol.26, pp.1-10,1993.

[8] S.R.Paranjothi, and K.Anburaja, "Optimal power flow using refined genetic algorithm", Electr.Power Compon.Syst, Vol. 30, 1055-1063, 2002.

[9] D. Devaraj, and B. Yeganarayana, "Genetic algorithm based optimal power flow for security enhancement", IEE proc-Generation. Transmission and. Distribution; 152, 6 November 2005.

[10] C.A. Canizares, A.C.Z.de Souza and V.H. Quintana, "Comparison of performance indices for detection of proximity to voltage collapse," vol. 11. no.3, pp.1441-1450, Aug 1996.

[11] Esmat Rashedi, Hossein Nezamabadipour, Saeid Saryazdi.GSA: A Gravitational Search Algorithm. Information Sciences, 179(13):2232-2248, 2009.

[12] Suman B, Kumar P. A survey of simulated annealing as a tool for single and multi-objective optimization. Journal of the Operational Research Society, 57 (10):1143-1160, 2006.

[13] El-Bouri A, Azizi N, Zolfaghari S.A comparative study of a new heuristic based on fitness memory programming and simulated annealing: the case of job shop scheduling.European Journal of Operational Research, 177:1894-1910, 2007.

[14] Tan K C, Chew Y H, Lee L H.A hybrid multi-objective evolutionary algorithm for solving truck and trailer vehicle routing problems.European Journal of Operational Research, 172:855$885,2006$.

[15] TONG Chengyi, Gravitational Search Algorithm Based on Simulated Annealing, Journal of Convergence Information Technology (JCIT) Volume9, Number2, March 2014.

[16] IEEE, "The IEEE 30-bus test system and the IEEE 118-test system", (1993), http://www.ee.washington.edu/trsearch/pstca/.

[17] Jiangtao Cao, Fuli Wang and Ping Li, "An Improved Biogeography-based Optimization Algorithm for Optimal Reactive Power Flow", International Journal of Control and Automation Vol.7, No.3 (2014), pp.161-176.

*Corresponding author.

E-mail address: gklenin@ gmail.com 